\title{
O papel da psiquiatria na reforma psiquiátrica
}

\author{
The role of psychiatry in the Brazilian psychiatric reform
}

Octavio Domont de Serpa Junior ${ }^{1}$

${ }^{1}$ Instituto de Psiquiatria, Universidade Federal do Rio de Janeiro (IPUB/ UFRJ). Av. Venceslau Brás 71/fundos, Botafogo. Rio de Janeiro RJ. 22290-140. domserpa@gmail.com

\begin{abstract}
Psychiatry emerged just over two hundred years ago as a special branch of medicine offering institutional care for the insane, since it encompassed the fields of medicine, natural history (biology) and philosophy (humanities). It appeared at a time marked by the transition with the exclusion apparatus of the marginalized people of the Old Regime and by epistemic pluralism. In this article, the contribution that psychiatry can make today - just over two centuries and some important conceptual and institutional rearrangements later - is discussed. It is well established in the academic world and socially legitimized, albeit at another moment of transition, in which new paradigms of care are established placing importance on the contextual and intersubjective situation of psychic distress. Redefining Pinelian intuition using contemporary vocabulary regarding the epistemological and ethical challenge of an area of knowledge and practice of care the scope of which is psychic distress, the thesis will be proposed that it is also necessary to articulate the planes of body, experience and narrative in an ongoing dialogue.
\end{abstract}

Key words Psychiatry, Psychiatric reform, Body, Experience, Narrative
Resumo A psiquiatria nasce há pouco mais de duzentos anos atrás se caracterizando como uma medicina especial que se oferece ao cuidado institucional do louco e atravessada pelos saberes da medicina, da história natural (biologia) e filosofia (humanidades). Ela nasce marcada pela ruptura do aparato de exclusão dos marginalizados do Antigo Regime e pela pluralidade epistêmica. Neste artigo é discutida a contribuição que a psiquiatria pode dar hoje, pouco mais de dois séculos e depois de alguns importantes remanejamentos conceituais e institucionais, assentada no universo acadêmico e socialmente legitimada, em um outro momento de ruptura, em que novos paradigmas de cuidado são estabelecidos valorizando a situação contextual e intersubjetiva do sofrimento psíquico. Repaginando em um vocabulário contemporâneo a intuição pineliana acerca do desafio ético e epistemológico de um saber e de uma prática de cuidados que tem como objeto o sofrimento psíquico, será defendida a tese de que a este saber e prática se impõe uma articulação dos planos do corpo, da experiência e da narrativa em uma interlocução permanente.

Palavras-chave Psiquiatria, Reforma psiquiátrica, Corpo, Experiência, Narrativa 


\section{Antecendentes}

Há pouco mais de duzentos anos, em um contexto de amplas reformas políticas e institucionais, a psiquiatria - ou medicina mental - emergia como uma "novidade" no campo das práticas médicas e sociais. Foi considerada a primeira especialidade da medicina ${ }^{1,2}$, menos pela particularidade do seu objeto (a alienação mental), mas sobretudo por se caracterizar como uma medicina especial, em função da singularidade do seu espaço institucional de exercício (o asilo), de suas práticas de cura (emprego do tratamento moral) e da persistência do modelo clínicosintomatológico, em contraposição ao modelo anátomo-clínico, que ascendia a uma posição hegemônica no restante da medicina.

Este acontecimento - o "nascimento da psiquiatria" - conhece pelo menos duas interpretações que dele fazem juízos de valor opostos. A primeira e mais conhecida delas, proposta por Foucault ${ }^{3}$, adotando uma perspectiva mais externalista, entende este evento como o ponto culminante de um processo de exclusão da desrazão, iniciado em meados do século XVII, por ocasião da "Grande Internação". Este movimento buscou exilar do cenário social e dos territórios de legitimidade do pensamento e da ação todas as figuras do desatino, tomadas de forma indistinta. No decorrer dos cerca de cento e cinquenta anos seguintes, o espaço institucional onde se operava a grande internação - o Hospital Geral - foi se esvaziando pouco a pouco, em função de transformações econômicas, sociais e políticas. Nesta trajetória, o rosto indiferenciado do desatino foi sendo pouco a pouco recortado em figuras mais precisas - correcionais, devassos, hereges, doentes crônicos, crianças e idosos abandonados, loucos - que voltavam ao convívio social ou eram destinadas a instituições específicas. Aos loucos foi destinado o Asilo, herdeiro do espaço físico ocupado pelo Hospital Geral. O Asilo, na interpretação foucaultiana, encarnava a forma mais perfeita de exclusão, agora visando exclusivamente a loucura, que liberta dos grilhões de ferro, torna-se cativa de um saber - a psiquiatria - que doravante falará em seu nome, silenciando-a para sempre. A loucura só pôde ser desvencilhada das correntes porque passou a ser imobilizada pela condição de doença mental.

A outra interpretação, proposta por Swain ${ }^{4} \mathrm{e}$ Gauchet e Swain ${ }^{5}$, adotando um ponto de vista que mescla internalismo com externalismo, sugere uma sintonia entre a emergência da medicina mental e as transformações sociais e políticas da virada do século XVIII para o século XIX, na passagem do Antigo Regime para a sociedade democrática liberal burguesa. Esta interpretação procura destacar uma "lógica da inclusão" subjacente à constituição da medicina mental, justificando a privação de liberdade do internamento no Asilo como um gesto de fraternidade que busca oferecer cuidado terapêutico a fim de restabelecer a igualdade conferida pela restituição da razão. Um dos sustentáculos desta posição é o estudo aprofundado de um personagem que figura como protagonista em todas as versões da história da psiquiatria, das mais hagiográficas às mais criticas, o médico francês Philippe Pinel.

A possibilidade de se pensar a loucura como curável, na perspectiva inaugurada por Pinel, se baseia na originalidade da leitura deste, que entendia a loucura sempre como parcial, ou seja, mesmo nas errâncias mais extremas da razão persistiria sempre um "sujeito" da loucura. Consequentemente, a presença da alienação mental não representava a passagem a um avesso da razão, mas uma contradição possível no seu interior, compatível com a persistência de uma fração subjetiva à qual se dirigia o alienista no seu trabalho terapêutico.

Apesar do seu antagonismo, as duas interpretações acerca do alvorecer da medicina mental em um momento histórico de tantas transformações não devem ser tomadas como mutuamente excludentes. Elas servem para balizar um horizonte ético que se descortinava desde este momento inaugural, e que continua a se oferecer à perspectiva dos praticantes até os dias de hoje. Por um lado, temos os riscos de uma objetificação extremada na produção do conhecimento da Clínica, que nasce necessariamente do acontecimento individual do sofrimento físico e moral, podendo levar a uma despossessão subjetiva tal que termina por perder de vista o próprio objeto deste conhecimento. E por outro lado, a necessidade de manter permanentemente em contato os aspectos mais abstratos e generalizantes do conhecimento com a as experiências subjetivas de padecimento psíquico que os fundamentam, sem esquecer que estas últimas necessariamente se articulam em uma trama de enlaces intersubjetivos e se enraízam em um ambiente simultaneamente físico, cultural e histórico. O bom exercício da psiquiatria só pode acontecer mantida esta tensão constitutiva, sem soluções de facilidade em uma ou outra direção.

Pinel reconhece, desde as primeiras páginas do seu Traité médico-philosophique sur l'aliénation mentale, que o conjunto de saberes e 
práticas das quais a sua obra representa a síntese inaugural deve se amparar sobre o conhecimento da medicina, da filosofia e sobre a prática junto aos pacientes. Para fazer face ao desafio do cuidado terapêutico da loucura, há que se reconhecer a complexidade ética e epistemológica da medicina mental e a necessidade de embasá-la nas ciências e nas humanidades.

Sintetizando, podemos dizer que a Psiquiatria já nasce sob o signo da reforma (ruptura do aparato de exclusão dos marginalizados do Antigo Regime), da pluralidade epistêmica e do engajamento ético. Pouco mais de dois séculos e alguns importantes remanejamentos conceituais e institucionais depois, assentada no universo acadêmico e socialmente legitimada, que tipo de participação a psiquiatria pode ter no campo da atenção ao sofrimento psíquico, agora que atravessamos um outro movimento de reforma, em que novos paradigmas de cuidado são estabelecidos?

\section{Apresentação do Problema}

Pretendo iniciar esta discussão partindo de duas citações que nos ajudarão a situar a linha argumentativa que devo seguir. A primeira delas é extraída de um livro de Giovanni Stanghellini ${ }^{7}$ e procura delimitar o escopo de interesses da Psicopatologia, ou, colocado de outro modo, do saber que deve fundamentar a Psiquiatria. Stanghellini ${ }^{7}$ sugere que a Psicopatologia deve ...iluminar primariamente a qualidade das experiências subjetivas, seus significados pessoais e o padrão pelo qual elas estão situadas como partes de totalidades significativas [...] principalmente concernida com a corporificação e a intersubjetividade. Esta passagem destaca de forma muito clara a extensão do desafio epistemológico da psiquiatria face à complexidade do seu objeto, que se estende da materialidade do corpo até ao vivido subjetivo, passando necessariamente pelo universo relacional.

Contudo, este conhecimento não se contenta com a mera contemplação. Ele é necessariamente prático, visa intervir e transformar a realidade. Aliás, é bem sabido que o saber psiquiátrico não precede as transformações institucionais que marcaram o advento da psiquiatria. Pelo contrário, ele emerge das novas condições do lidar com a loucura na passagem do século XVIII para o século XIX. Logo, saber e saber-fazer estão indissociavelmente ligados na trajetória da psiquiatria desde a sua origem. E aqui passo à minha segunda citação, que revela de forma sucinta e elegante esta síntese. Trata-se de uma passagem de Canguilhem ${ }^{8}$, extraída do início de "O Normal e o Patológico”. Embora se refira à medicina em sua generalidade, acredito que podemos transpor sem prejuízos para a psiquiatria, ou qualquer prática clínica em particular, a definição que este autor propõe para a medicina. Esta, no seu entendimento, corresponde a uma ...técnica ou arte de instauração e restauração do normal, situada na confluência de várias ciências e saberes, não redutível a uma dimensão exclusivamente cognitiva.

Por restauração e instauração do normal não devemos entender uma restitutio ad integrum ao status quo ante, mesmo porque na vida não há reversibilidade, e nem tampouco uma redução de subjetividades a padrões de performance préestabelecidos em escalas e protocolos. Trata-se, em vez disso, do restabelecimento de uma normatividade propiciadora da reinvenção das relações do organismo humano com o seu meio natural, social e cultural. Mas o que eu gostaria de destacar no presente contexto de argumentação é a indicação de que as práticas clínicas e terapêuticas, a psiquiatria incluída, são menos da ordem da fidelidade epistemológica a diferentes regiões da ciência (principalmente das ciências naturais), regidas pelos seus respectivos reducionismos metodológicos, do que da ordem de uma prática ou saber-fazer informada por diferentes ciências (naturais, sociais e humanas), em um procedimento que não se esgota no plano do conhecimento, mas envolve necessariamente as dimensões intuitivas e empáticas.

Isto se torna mais fácil de apreender se, ainda com Canguilhem ${ }^{8}$, atentamos para o fato que ...o fato patológico só pode ser apreendido enquanto tal ao nível da totalidade orgânica; e, em se tratando de organismos humanos, ao nível da totalidade individual consciente (...) Ser doente é, para o homem, viver uma vida diferente, mesmo no sentido biológico. A abordagem pragmática de qualquer enfermidade, seja física ou mental, ainda que deva reconhecer o plano de sua inscrição corporal e nele intervir, não pode ignorar que a doença é sempre, em alguma medida, vivida experiencialmente. Não custa nada lembrar que patológico deriva de pathos, "...sentimento direto e concreto de sofrimento e de impotência, sentimento de vida contrariada”. Esta experiência é sempre dotada de sentido, inscrita em alguma trama de significações, em outras palavras, inserida em alguma construção narrativa que a situa na trajetória biográfica de cada sujeito.

Repaginando em um vocabulário contemporâneo a intuição pineliana acerca do desafio ético 
e epistemológico de um saber e de uma prática de cuidados que tem como objeto o sofrimento psíquico, eu diria que a este saber e prática se impõe uma articulação dos planos do corpo, da experiência e da narrativa em uma interlocução permanente. O problema que se apresenta é como pensar esta relação em um momento em que a psiquiatria "redescobre" o cérebro e se encontra fortemente marcada pela biomedicina, e, ao mesmo tempo, seus cenários de prática passam por um movimento de reforma e transformação? Para exercitar esta reflexão proponho então que examinemos na sequência deste artigo estas três noções - corpo, experiência e narrativa - e como elas se entrelaçam em uma relação de influência mútua (Figura 1).

\section{Corpo}

A modalidade mais comum de apreensão do corpo nas práticas médica e psiquiátrica é daquele enquanto Corpo Objetivo, tomado da perspectiva da 3a pessoa - Körper'. Ou seja, um corpo examinado à distância, mesmo que à distância do olhar ou até mesmo do toque, mas cuja aproximação é sempre mediada, instrumentalmente ou não. É um corpo estático, metaforicamente falando é o corpo do cadáver, da anátomo-clínica, congelado em sua dinâmica e estagnado em seu fluxo. Ainda que haja dinâmica e movimento no corpo tomado como objeto, estes serão sempre tomados como contrações, espasmos ou comportamentos, sem lugar para intenções, ações ou experiências. O corpo objetivo é um corpo universal, atemporal, não marcado pelo contexto, pelas práticas culturais, pela trajetória bio-

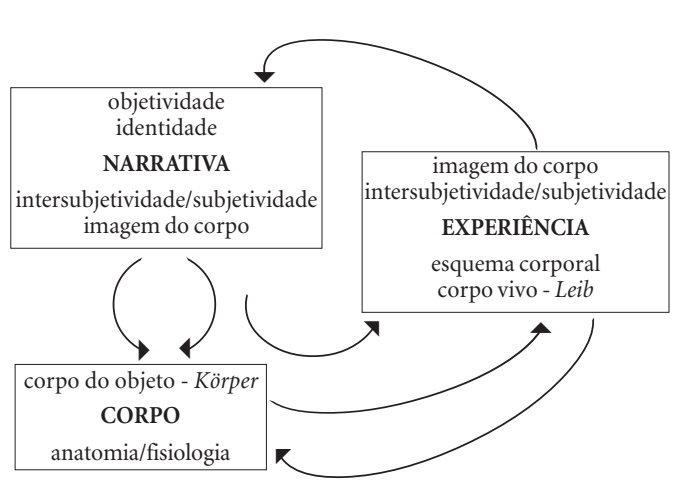

Figura 1. gráfica. Congelado, fora do tempo e situado em um espaço abstrato, o corpo objetivo é tomado em suas partes e fragmentos sem que se considere qualquer prejuízo ao seu estudo e ao conhecimento dele decorrente.

No caso da psiquiatria, o cérebro - e as localizações cerebrais - é o fragmento destacado da totalidade orgânica ao qual são dirigidas todas as atenções. Acompanhando os extraordinários desenvolvimentos nas neurociências nos últimos 30 anos, a psiquiatria redescobre o cérebro e nele acredita residirem todas as respostas para os seus enigmas e saídas para os seus impasses. Testemunhamos o despertar de uma versão intuitiva de um fisicalismo reducionista ${ }^{10}$, que sustenta a crença de que transtornos mentais nada mais são do que afecções do cérebro e que conhecimentos e práticas que valorizam a subjetividade e as relações humanas são de segunda linha e em breve poderão ser definitivamente descartados.

Entretanto, por maior que seja o apelo desta concepção fisicalista do transtorno mental, sobretudo entre a geração mais nova de psiquiatras, não posso deixar de indagar: cérebros - ou qualquer outro órgão da anatomia - adoecem? Se à doença corresponde, como lembra Cangui$\mathrm{lhem}^{8}$, um sentimento de vida contrariada, como pensar um sentimento ou qualquer outro evento mental referido a um órgão destacado do organismo, seja ele o cérebro ou não. Estados mentais remetem necessariamente à totalidade subjetiva e orgânica. Quem adoece são pessoas com cérebro. Para abordar o sofrimento psíquico não podemos contornar a subjetividade!

O credo fisicalista, reducionista, localizacionista não é, contudo, unânime nem mesmo no campo da pesquisa neurocientífica. Alguns autores que trabalham sobretudo investigando os fundamentais cerebrais da experiência consciente têm desafiado esta posição sugerindo, com base em dados clínicos e de pesquisa empírica, uma compreensão holista e organísmica do funcionamento do cérebro e uma compreensão emergentista para as relações mente-cérebro ${ }^{10}$. Neste cenário, eu destacaria especialmente a teoria enativa de Francisco Varela ${ }^{11-13}$ que indica caráter necessariamente corporal, situacional e ativo da constituição da experiência mental: mente e mundo emergem simultaneamente como resultado da interação recíproca entre organismo e meio. A vida psíquica depende dos tipos de experiência que resultam do fato de possuirmos/ habitarmos um corpo com determinadas capacidades sensório-motoras, por um lado, e do fato de as próprias capacidades sensório-motoras es- 
tarem embasadas num contexto biológico, psicológico e cultural mais amplo, por outro. Dito de outra maneira, o corpo biológico habilita ou impossibilita, pela sua estrutura, postura e capacidade motora a maneira pela qual percebemos, agimos e pensamos sobre o mundo

A teoria enativa, desenvolvida por Varela e colaboradores $^{11-14}$, oferece ferramentas conceituais interessantes para pensarmos uma prática clínica que pode superar as barreiras dualistas que colocam mente e corpo como dois universos totalmente dissociados entre si e do entorno. Uma melhor concepção de cérebro, corpo e ambiente seria a de sistemas mutuamente enraizados em vez de interna e externamente localizados com relação uns aos outros ${ }^{14}$.

Um autor na história recente da psiquiatria e da neurologia desenvolveu linha de pensamento bastante afim, mas que se encontra hoje em dia praticamente esquecido. Refiro-me a K. Goldstein, neuropsiquiatra alemão que começou a sua carreira clínica e de pesquisador junto a militares que retornavam do front da Primeira Grande Guerra, portadores de lesões cerebrais. Este trabalho clínico de Goldstein lhe permitiu elaborar não só uma vigorosa crítica ao localizacionismo cerebral, ainda hegemônico no início do século XX, mas também produzir uma teoria sobre cérebro, corpo e ambiente rica em intuições clínicas $^{15}$. Ele sugere, inspirado pela noção de Umwelt, de von Uexkullit ${ }^{16}$ que o ambiente é extraído do mundo pela existência do organismo: “...um organismo só pode existir se ele consegue encontrar, se ele consegue talhar, no mundo, um ambiente adequado" ${ }^{15}$. Esta relação organismo-ambiente é entendida como fundamental na história de um processo de adoecimento, na medida em que o acontecimento mórbido não é mais visto como uma espécie natural de existência intrínseca, mas sim como o resultado de formas de relação entre organismo e meio. As manifestações de uma doença deixam de ser entendidas como o acometimento de alguma parte isolada do corpo para serem compreendidas como respostas do organismo como um todo às solicitações do ambiente: Os sintomas são respostas que o organismo dá a certas questões bem determinadas que lhe são colocadas ${ }^{15}$. Os sintomas que o médico encontra correspondem às respostas que o organismo dá ao tipo de pergunta que a matriz teórica e o ambiente institucional aos quais se filia o examinador lhe autorizam a fazer. As concepções de saúde-doença e a organização institucional dos cuidados não são indiferentes, portanto, mesmo em um plano de compreensão restrito ao corpo, ao organismo, às manifestações sintomáticas e ao curso evolutivo das diferentes patologias. O exercício profissional em um ambiente hospitalar fechado e totalizante, orientado pela crença na incurabilidade, na incapacidade e na irresponsabilidade do doente mental não vai encontrar outra coisa que não desolação, mortificação e cronicidade. Por outro lado, a prática no território, em serviços abertos, atenta aos "pedaços de mundo" que cada sujeito escava para si mesmo na geografia geral, sem negar o sofrimento que justifica os cuidados, pode se surpreender com o que ainda existe de vida, criação e possibilidade de vínculos.

\section{Experiência}

Começamos a seção anterior nos reportando ao corpo examinado da perspectiva da terceira pessoa, o corpo objetivo (Körper). Na sequência, vimos que mente e corpo não devem ser tomados de forma completamente dissociada; pelo contrário, que a mente emerge da interação do corpo com o meio, que a subjetividade é sempre encarnada.

Isto nos remete à outra dimensão do corpo, discernida pela fenomenologia ${ }^{9}$, o corpo vivido (Leib), apreendido da perspectiva da primeira pessoa. O corpo vivido é o meu corpo, experienciado por dentro, aqui e agora, fonte dos meus pensamentos, desejos, emoções sensações. O corpo que oferece a perspectiva através da qual descortino e mergulho no mundo, é o corpo da autocentralização, o grau zero da experiência ${ }^{17}$. A subjetividade experiencial é sempre corporificada e situada. O sujeito da experiência, em seus aspectos mais fundamentais, é antes de mais nada um habitante da própria carne. Consequentemente, podemos afirmar que, complementando a observação feita na seção anterior, para abordar o sofrimento psíquico não podemos contornar a subjetividade, e nem tampouco o corpo!

A experiência começa no que poderíamos chamar de um self mínimo ou básico, comportando pelo menos dois aspectos emergentes desta relação do corpo com o mundo: a experiência de propriedade (sense of ownership), do self ecológico aberto ao ambiente por meio de aferências sensoriais multimodais (proprioceptivas, cinestésicas, visuais, auditivas, táteis etc); e a experiência de agentividade (sense of agency): self agentivo, que navega no mundo integrando ação e percepção, sustentado por esquemas corporais que regulam postura e movimento à serviço da ação intencional ${ }^{17-19}$. Temos aqui uma autocons- 
ciência imediata (awareness), corporal, pré-reflexiva, não temática, não conceitual.

Neste estrato mais elementar, a experiência corresponde ao ponto de vista da primeira pessoa no sentido mais estrito ${ }^{20,21}$, tal como ilustrado pela pergunta celebrizada por Thomas $\mathrm{Na}$ $\mathrm{gel}^{22}$ : What is it like to be...?, pura subjetividade que se constitui como aspecto ou função do modo de doação da experiência (first-personal givenness). Trata-se da experiência pura, totalizada e imediata dos estados mentais, aquém de qualquer reconhecimento ou nomeação dos mesmos, corrente de consciência que ainda não foi alcançada pela rede da reflexão $0^{23}$.

Neste plano mais fundamental da experiência, de uma perspectiva de primeira pessoa, estamos, como vimos acima, aquém da comunicação. Trata-se de uma singularidade absoluta, que ainda clama por um campo inicial de significação. Para tornar isto possível é necessário passarmos a uma região de interseção das perspectivas da primeira e da segunda pessoa (figura 2). Da primeira, guardamos o caráter singular e a apresentação idiossincrática da experiência. A segunda oferece as possibilidades dialógica e de significação por meio do movimento reflexivo e da inserção em uma comunidade linguística. É daí que nasce a possibilidade de reconhecer, nomear, descrever e comunicar a experiência. Tomemos como exemplo experiências que são descritas e comunicadas como "ouvir vozes". Estas correspondem a transformações muito fundamentais da experiência de si, tais como: diminuição da auto-afecção acompanhada de hiperreflexividade ${ }^{24}$; dissociação da experiência de propriedade e agentividade; modificações sutis na dinâmica da consciência íntima do tempo, principalmente em seus aspectos protensionais ${ }^{25}$. Em princípio, em nenhuma delas existe uma dimensão sensorial acústica implicada, que justificasse o emprego do verbo "ouvir" para comunicá-las. Trata-se de um uso metafórico que serve para expressar a estranheza de uma experiência de autoalienação quando tomada reflexivamente e articulada com os recursos da linguagem.

A experiência vivida, contudo, sempre excede as possibilidades descritivas e comunicacionais que se oferecem para relatá-la. Ela nunca se esgota na descrição que lhe é oferecida. Por outro lado, devemos reconhecer que os recursos narrativos, além de descrever ou expressar, também podem modificar o vivido imediato da experiência de algum modo, ordenando, estabilizando, e até modificando o seu conteúdo cognitivo e o seu colorido afetivo ${ }^{26}$.
Isto lança uma pergunta acerca das relações de pertinência que podem haver entre a forma e as condições estruturais da experiência e o conteúdo narrativo expressado. Quais são as pontes entre experiência singular e cultura? Kraus ${ }^{27}$, por exemplo, indaga por que é tão comum, em nossa cultura, a expressão de vividos alucinatórios e delirantes por meio de metáforas alusivas a um aparato técnico, da máquina de influenciar ao implante de chips. Ele levanta a hipótese de uma homologia entre a estrutura fenomenológica da experiência na psicose e o funcionamento destes apetrechos culturais. E com este questionamento vamos deslizando para o nosso próximo estrato de análise, o plano das narrativas.

\section{Narrativa}

Começamos com o corpo, primeiro em sua objetividade e materialidade orgânicas, examinado de uma perspectiva de terceira pessoa. Em seguida, passamos para o corpo vivido, sede e condição do sujeito experiencial ${ }^{21}$ : corpo e experiência se entrelaçando em uma perspectiva de primeira pessoa, que não se esgota em si mesma e que, ao ser posta em palavras, se abre para a perspectiva da segunda pessoa, da reflexão e da linguagem. A singularidade radical da experiência traduzida e compartilhada por meio de uma narrativa tece os vínculos entre o indivíduo e a cultura, integrando as três perspectivas: primeira, segunda e terceira pessoa (Figura 2). Emerge da experiência singular, pontual e momentânea a possibilidade de se construir um sujeito narrativo, extenso e autobiográfico, dotado de uma identidade. Como indica Ricoeur ${ }^{28}$, "a narrativa faz parte da vida antes de se exilar na escrita".

Como já foi indicado na seção anterior, o sujeito narrativo pressupõe o reconhecimento (julgamento e atribuição) e a comunicação da experiência. Ele é, portanto, sempre reflexivo e intersubjetivo. A abertura para a intersubjetividade, que vai se estender pela tessitura narrativa, também começa no corpo, pela mediação entre o corpo vivido (ipseidade) e o corpo objetivo (alteridade), sugerindo, na própria morada corporal, a presença dos outros habitantes do mundo. O corpo do sujeito narrativo é o da imagem do corpo: experiências, atitudes e crenças nos quais o objeto intencional é o próprio corpo ${ }^{21}$, nas quais as marcas da história, da cultura e dos valores se fazem imprimir.

O sujeito narrativo, como a própria expressão indica, é construído na e através da narrati- 
va, em uma construção aberta, sujeita a constantes revisões, referida aos valores, ideais e objetivos ancorados em uma dada cultura, organizando e dando sentido às experiências vividas singularmente. O sujeito narrativo é o narrador e o personagem de uma vida da qual é no máximo coautor $^{28}$.

Duas principais modalidades de sujeito narrativo são reconhecidas na produção acadêmica contemporânea ${ }^{29-31}$. A primeira delas é a do sujeito narrativo abstrato $^{32}$, que a partir de uma arena de debates que tinha como foco a desconstrução do dualismo e materialismo cartesiano, propõe o entendimento do self como um centro de gravidade narrativa, uma ficção teórica, um objeto abstrato para o qual convergem as várias narrativas que tem o sujeito por personagem, seja ele ou não o autor. A segunda modalidade é a do sujeito narrativo corporificado ${ }^{28}$, mais próxima da direção argumentativa que estou seguindo neste texto, e que entende o sujeito ou identidade narrativa como o ponto de articulação dos dois pólos de permanência do self no tempo: mesmidade (o quê?) e ipseidade (quem?). Para Ri$\operatorname{coeur}^{28}$ a corporificação estrutura a experiência e a cognição enquanto uma perspectiva interna contínua no tempo, servindo como fundamento para a produção da narrativa, que por sua vez funciona como a síntese do heterogêneo, a "concordância discordante”.

Entre as muitas "discordâncias" com que a vida nos surpreende e nos conclama a integrar na síntese narrativa, a experiência do adoecimento é das mais contundentes, especialmente no caso dos transtornos mentais mais graves, que atingem a subjetividade na sua inteireza. Não podemos esquecer, como aponta Kleinman ${ }^{33}$, que a narrativa serve para dar sentido, contexto e perspectiva para os problemas do paciente, definindo como e por que ele está doente. A experiência do adoecimento inclui a procura por explicações, categorizações, relações temporais, espaciais, de similaridade, das modalidades de sofrimento produzidas pelos processos patofisiológicos, sejam eles físicos ou mentais. Por isso, na prática dos cuidados é preciso tomar as construções narrativas individuais e culturais como parte integrante do trabalho clínico. O sentido de um processo de adoecimento não se esgota no conhecimento biomédico. As enfermidades são po-

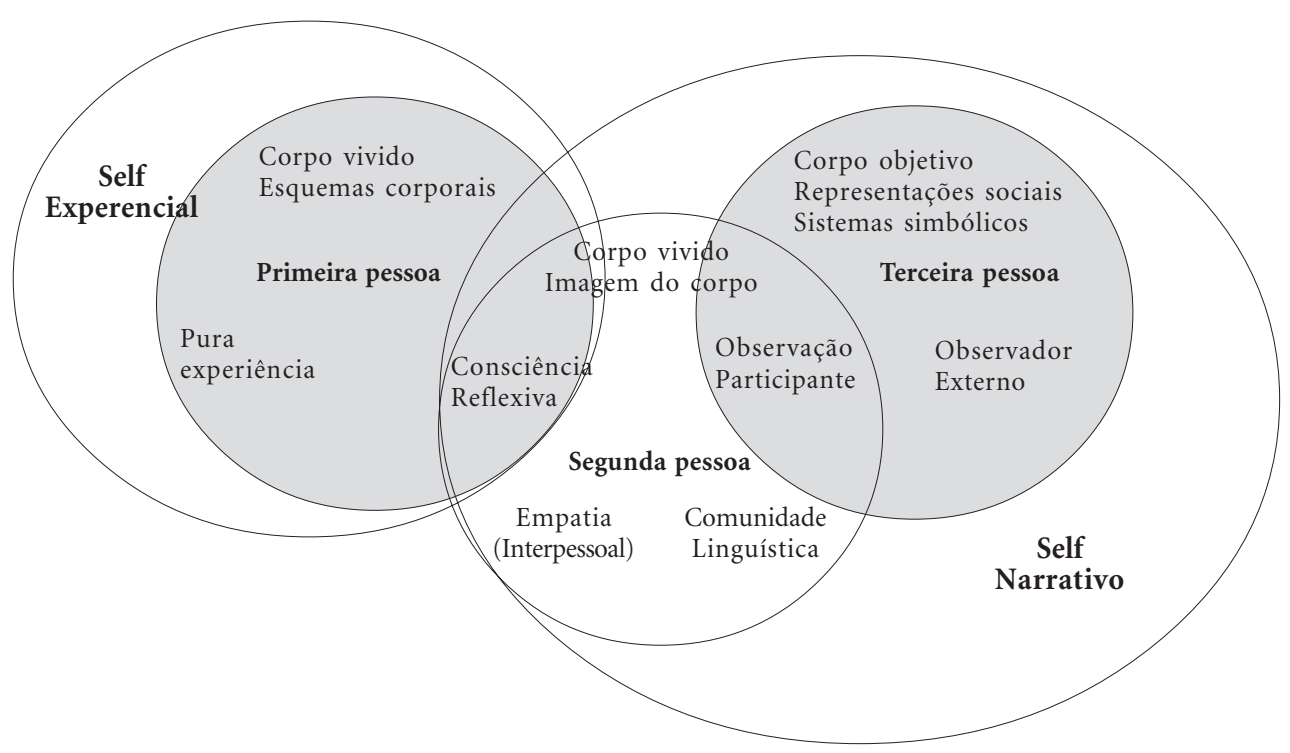

Figura 2. 
lissêmicas, revelam ou ocultam mais de um significado. Estes significados, produzidos no processo de construção da narrativa - e que são frequentemente minimizados, ignorados ou silenciados pelo psiquiatra - podem ampliar ou amenizar sintomas ou incapacidades, podem impedir ou viabilizar tratamentos.

\section{Considerações finais}

Entendo que uma psiquiatria que se conserve fiel ao horizonte ético e epistemológico inaugurado por Pinel, no alvorecer do século XIX, que não se intimide diante das exigências que lhe são impostas pela complexidade do seu objeto e que não se contente com soluções de facilidade reducionistas, deverá ser capaz de integrar em sua prática os três planos de compreensão que fundamentam a prática clínica em sua interrelação recíproca e que busquei caracterizar neste ensaio: corpo, experiência e narrativa (Figura 1).
A integração destes planos nos permite compreender como, no contexto humano da enfermidade, a experiência singular do padecimento emerge dos processos desordenados do corpo e clama pelo sentido a ser tecido pela prática intersubjetiva de construção da narrativa. As possibilidades que se abrem ou se fecham, de elaboração de sentido, podem modificar a experiência, levando tanto ao apaziguamento do sofrimento quanto à mortificação e à estigmatização, dependendo do que o cenário relacional e humano permitir elaborar. Dependendo do valor negativo ou positivo da experiência reformulada pela produção de sentidos, o corpo sofre ainda mais ou se regozija.

A psiquiatria capaz de operar clínica e conceitualmente desta maneira decerto tem um papel importante a desempenhar no processo da reforma psiquiátrica, de produção de novos paradigmas clínicos e de criação de outros cenários de cuidado. 


\section{Referências}

1. Castel R. A ordem psiquiátrica: a idade de ouro do alienismo. Rio de Janeiro: Graal; 1978.

2. Serpa Junior. OD. Lacunas e dobras: das relações da medicina com a psiquiatria. In: Russo J, Silva Filho JF, organizadores. Duzentos anos de psiquiatria. Rio de Janeiro: Ed. UFRJ, Relume Dumará; 1993. p. 97-107.

3. Foucault M. História da loucura na idade clássica. São Paulo: Perspectiva; 1978.

4. Swain G. Le Sujet de la Folie. Naissance de la psychiatrie. Privat: Toulouse; 1977.

5. Gauchet M, Swain G. La pratique de l'esprit humain. L'institution asilaire et la revolution démocratique. Paris: Gallimard; 1980.

6. Swain G. Une logique de l'inclusion: les infirmes du signe. In: Swain G, organizador. Dialogue avec l'insensé. Paris: Gallimard; 1994.

7. Stanghellini G. Disembodied spirits and deanimated bodies. The psychopathology of common sense. Oxford: Oxford University Press; 2004.

8. Canguilhem G. O Normal e o Patológico. Rio de Janeiro: Forense Universitária; 1982.

9. Aho J, Aho K. Body Matters. A phenomenology of sickness, disease, and illness. Plymouth: Lexington Books; 2009.

10. Serpa Junior O D. Psiquiatria e neurociências: como "redescobrir" o cérebro sem eclipsar o sujeito. Revista Latinoamericana de Psicopatologia Fundamental 2004; 7(2):110-124.

11. Varela FJ, Thompson E, Rosch E. The Embodied Mind. Cognitive Science and Human Experience. Cambridge: MIT Press; 1993.

12. Varela FJ. Invitation aux sciences cognitives. Paris: Éditions du Seuil; 1996.

13. Varela FJ, Thompson E. Neural Synchrony and the Unity of Mind: A Neurophenomenological Perspective. Oxford: Oxford University Press; 2003.

14. Thompson E, Varela FJ. Radical embodiment: neural dynamics and consciousness. Trends in Cognitive Sciences 2001; 5(10):418-425.

15. Goldstein K. La Structure de l'Organisme. Paris: Gallimard; 1983.

16. von Uexkull J. Mondes animaux et monde humain. Paris: Denoël; 2004.

17. Gallagher S, Zahavi D. The Phenomenological Mind. An introduction to philosophy of mind and cognitive science. London: Routledge; 2008.

18. Gallagher S. Agency, ownership, and alien control in schizophrenia. In: Zahavi D, Grunbaum T, Parnas J, organizadores. The Structure and Development of SelfConsciousness. Interdisciplinary perspectives. Amsterdam: John Benjamins; 2004. p. 89-104.

19. Gallagher S. How the body shapes the mind. Oxford: Oxford University Press; 2005.

20. Northoff G, Heinzel A. The self in philosophy, neuroscience and psychiatry: an epistemic approach. In: Kircher T, David AS, organizadores. The Self in Neuroscience and Psychiatry. Cambridge: Cambridge University Press; 2003. p. 40-55.
21. Zahavi D. Subjectivity and Selfhood. Investigating the first-person perspective. Cambridge: MIT Press; 2005.

22. Nagel T. What is it like to a bat? In: Block N, Flanagan O, Guzeldere G, organizadores. The Nature of Consciousness. Philosophical Debates. Cambridge: MIT Press; 1997. p. 519-527.

23. Schutz A. On Phenomenology and social relations. Chicago: The University of Chicago Press; 1970.

24. Sass LA, Parnas J. Explaining schizophrenia: the relevance of phenomenology. In: Chung MC, Fulford KWM, Graham G, organizadores. Reconceiving Schizophrenia. Oxford: Oxford University Press; 2006. p. 63-95.

25. Gallagher S. Neurocognitive Models of Schizophrenia: A Neurophenomenological Critique. Psychopathology 2004; 37(1):8-19.

26. Good B. Medicine, Rationality and Experience. An anthropological perspective. Cambridge: Cambridge University Press; 1994.

27. Kraus A. Existential a prioris and the phenomenology of schizophrenia Dial Phil Ment Neuro Sci 2010; $3(1): 1-7$.

28. Ricoeur P. Soi-même comme un autre. Paris: Seuil; 1990.

29. Gallagher S. Philosophical conceptions of the self: implications for cognitive sciences. Trends in $\mathrm{Cog}_{-}$ nitive Science 2000; 4(1):14-21.

30. Thornton T. Psychopathology and Two Kinds of Narrative Account of the Self. Philosophy, Psychiatry and Psychology 2003; 10(4):361-367.

31. Menary R. Embodied Narratives. Journal of consciousness studies 2008; 15(6):63-84.

32. Dennett $D$. The self as a center of narrative gravity. In: Kessel F, Cole P, Johnson D, organizadores. Self and consciousness: multiple per- spectives. Hillsdale: Erlbaum; 1992.

33. Kleinman A. The illness narratives. Suffering, healing and the human condition. New York: Basic Books; 1988.

34. Depraz N, Cosmelli, D. Empathy and openness: practices of intersubjectivity at the core of the science of consciousness. In: Thompson E, organizador. The Problem of Consciousness. Calgary: Calgary University Press; 2003. p. 163-203.

Apresentado em 08/09/2011

Aprovado em 30/09/2011

Versão final apresentada em 05/10/2011 